\title{
Overweight and obesity and its socio- demographic correlates among urban Ethiopian women: evidence from the 2011 EDHS
}

Solomon Abrha', Solomon Shiferaw² and Kedir Y. Ahmed ${ }^{3 *}$

\begin{abstract}
Background: Evidences show that the burden of overweight and obesity is increasing in developing countries, particularly among urban women. Despite this worrying trend and the recognition of the emerging problem of chronic diseases in the recently launched Health Sector Transformation Plan of Ethiopia, little efforts are being made to address overweight and obesity. The present study aimed at assessing the prevalence and socio-demographic correlates of overweight and obesity among urban women.

Methods: This study was based on the 2011 Ethiopian Demographic Health Survey (EDHS) that used a two-stage stratified cluster sampling technique. A total of 3602 non-pregnant urban reproductive age women were included in the analysis. Simple descriptive, bivariate and multiple logistic regression analysis were employed as appropriate.

Results: The prevalence of overweight and obesity among urban Ethiopian women was found to be 435 (12.1\%) and $99(2.8 \%)$, respectively. Urban women in the age groups from 20-29 years [Adjusted Odds Ratio (AOR) $=2.3$ $95 \% \mathrm{Cl}: 1.4,3.9], 30-39$ years ( $\mathrm{AOR}=5.095 \% \mathrm{Cl}: 2.9,8.8)$ and $40-49$ years ( $\mathrm{AOR}=9.895 \% \mathrm{Cl}$ : 5.1, 13.8) were significantly more likely to have overweight and obesity compared to the youngest age group (15 to 19 years). The odds of being overweight and obese was significantly higher among women in the richest quintile (AOR $=1.8$ $95 \% \mathrm{Cl}: 1.1,2.5)$, those with secondary and above education (AOR $=2.095 \% \mathrm{Cl}:(1.3,3.1)$ and married women $(\mathrm{AOR}=2.095 \% \mathrm{Cl}:(1.2,3.3)$.

Conclusions: The prevalence of overweight and obesity was found to be higher in urban women compared to the national average. Being married, older, belonging to the richest quintile, living in the three metropolises (Addis Ababa, Harari and Dire Dawa), and with secondary and above educational level are independent predictors of overweight and obesity. Programs that target on older, educated and well to do women, and those living in the big cities are expected to cope with this substantial public health concern.
\end{abstract}

Keywords: Overweight, Obesity, Urban Ethiopian women

\footnotetext{
*Correspondence: kedirymam331@gmail.com

${ }^{3}$ Department of Public Health, College of Medicine and Health Science,

Debre Markos University, PO Box: 269, Debre Markos, Ethiopia

Full list of author information is available at the end of the article
}

(c) 2016 The Author(s). Open Access This article is distributed under the terms of the Creative Commons Attribution 4.0 International License (http://creativecommons.org/licenses/by/4.0/, which permits unrestricted use, distribution, and reproduction in any medium, provided you give appropriate credit to the original author(s) and the source, provide a link to the Creative Commons license, and indicate if changes were made. The Creative Commons Public Domain Dedication waiver (http://creativecommons.org/publicdomain/zero/1.0/) applies to the data made available in this article, unless otherwise stated. 


\section{Background}

The global prevalence of overweight and obesity has been significantly increasing over the past four decades. The combined prevalence of overweight and obesity has increased by $27.5 \%$ for adults and $47.1 \%$ for children between 1980 and 2013. During this period, the proportion of women with overweight and obesity has also increased from 29.8 to $38.0 \%$ [1]. Excess body weight is a major risk factor for mortality and morbidity from cardiovascular diseases, diabetes, cancers and musculoskeletal disorders [2, 3]. In 2010, it was estimated that 3.4 million global annual deaths, $3.9 \%$ of years of life lost and $3.8 \%$ of global disability adjusted life years (DALYs) were caused by overweight and obesity [1, 4, 5]. Once associated only with high-income countries, overweight and obesity are now also prevalent in low and middle-income countries and more noticeably in urban areas [6-8].

Evidences show that the burden of overweight and obesity is increasing in developing countries, particularly among urban women. Also, women in developing countries have higher rates of overweight and obesity than men and this relationship persisted over time [1, 9-11]. Women's overweight doubled from $9 \%$ in 1980 to $18 \%$ in 2008 while obesity more than doubled from 2 to $5 \%$ over the same time period [12]. The rates are also increasing at alarming rates in Sub-Saharan Africa [13]. In 2013, the prevalence of overweight and obesity among women in Eastern Sub-Saharan African countries was 23.7 and $8.8 \%$, respectively [1]. Similarly, a Nigerian study based on demographic and health survey data showed, about $36.4 \%$ of urban women had either overweight or obesity [14].

A number of studies conducted on chronic diseases risk factors showed an increase in the prevalence of overweight and obesity in Ethiopia [15-19]. A study based on Ethiopian Demographic Health Survey (EDHS) data showed that the prevalence of overweight increased by $28 \%$ (from $16.1 \%$ in 2000 to $20.6 \%$ in 2011) among women in Addis Ababa [20]. A similar study showed that one-third of female permanent commercial bank employees and public school teachers in Addis Ababa were either overweight or obese [19].

Despite this worrying trend and the recognition of the emerging problem of chronic diseases as a national public health concerns in the recently launched Health Sector Transformation Plan of Ethiopia [21], little efforts are being made to address overweight and obesity [3]. Moreover, given the fact that the changes favoring unhealthy dietary pattern and limited physical activity are associated with urbanization, the prevalence of overweight and obesity in urban areas is consistently higher compared to rural areas [22-24]. Therefore, the present study aimed at assessing the prevalence and socio- demographic correlates of overweight and obesity among urban non-pregnant reproductive age women in Ethiopia.

\section{Methods}

\section{Study design and data sources}

This cross-sectional study was based on the 2011 Ethiopia Demographic and Health Survey (EDHS), which was designed as a nationally representative survey. The survey provided data on a wide range of indicators relating to population, health, and nutrition. It was funded by the United States Agency for International Development, the Government of Ethiopia with other stake holders and implemented out by the Central Statistical Agency (CSA).

\section{Sampling techniques and population}

The survey employed two-stage stratified cluster sampling technique. The country is structured into nine regional states and two City Administrations Councils (Addis Ababa and Dire Dawa). Stratification was achieved by separating each region and one of the town administrations into urban and rural areas, except the entirely urban Addis Ababa. In total, 23 sampling strata have been created. Each stratum was further divided into enumeration areas (EAs) using the list of all EAs (clusters) prepared by the 2007 Population and Housing Census (PHC) as a sampling frame. In the first stage, a total of 624 EAs were selected, of which 187 were from urban areas. The EAs were selected with probability proportional to the EA size and with independent selection in each sampling stratum. Households comprised the second stage of sampling in which a fixed number of 30 households were selected for each EAs [25, 26]. Women who were pregnant and those with outlier BMI value $<12.00 \mathrm{~kg} / \mathrm{m}^{2}$ and $>50.00 \mathrm{~kg} / \mathrm{m}^{2}$, were excluded from this study. Overall, 3, 602 urban non-pregnant women of aged 15-49 years were included in the final analysis.

\section{Data collection}

The data collection procedure for the 2011 Ethiopian Demographic and Health Survey was documented in the full report [26]. Before the actual analysis was carried out the dataset was explored by running frequencies of available predictor variables, and weight/height variables. During exploration, it was noted that weight or height were measured for 3606 urban non-pregnant women. Of these, two outlier cases and two flagged cases were excluded from the final analysis. Socio-demographic characteristics of the women such as region of residence, age, marital status, educational status, occupation, wealth status and parity were the predictor variables for which data were collected. 


\section{Operational definitions}

- Body mass index (BMI): Weight in kilograms divided by height in meters squared.

- Overweight: $\mathrm{BMI}>=25.00 \mathrm{Kg} / \mathrm{m}^{2}$ and $<=29.99 \mathrm{Kg} / \mathrm{m}^{2}$

- Obese: $\mathrm{BMI}>=30.00 \mathrm{Kg} / \mathrm{m}^{2}$ and $<=50.00 \mathrm{~kg} / \mathrm{m}^{2}$

- Overweight and obese: $\mathrm{BMI}>=25.00 \mathrm{Kg} / \mathrm{m}^{2}$ and $<=50.00 \mathrm{Kg} / \mathrm{m}^{2}$. The outcome variable was dichotomized as: Overweight and obese (Yes) compared to the reference of normal and underweight groups (No).

- Region of residence was recoded as 'The three Metropolis' (which include Addis Ababa, Harari and Dire Dawa), Tigray, Amhara, Oromia, SNNPR and "Other regions" (which include Afar, Benshangul-Gumuz, Gambela and Somali).

- Kebele: the smallest administrative unit in Ethiopia.

- Woreda (district): an administrative unit which consists of kebeles

- EA (Clusters): An EA is a geographic area consisting of a convenient number of dwelling units which served a counting unit for the census.

- Flagged cases: inconsistent measurements noted for weight and height.

\section{Statistical analysis}

Complex sample analysis was performed using SPSS version 16.0 statistical software to account for the multistage cluster study design. The design variables of primary sampling unit (EAs) as cluster and stratification variable (residence) as strata were used. Analysis was carried out based on the weighted count. Sample weight was an eight digit variable with six implied decimal places and was divided by 1,000,000 before applying the weighting factor.

Frequencies and proportions were computed for description of the study population in relation to selected socio-demographic variables. Wealth index quintiles were constructed using principal component analysis. Multiple logistic regression analysis was used to identify independent predictors and control for confounding. Results were presented in the form of odds ratios (OR) and $95 \%$ confidence intervals. Statistical significance was set at a p-value of 0.05 . The overall model fitness test statistics with adjusted Wald chi-square value of 74.263 ( $p$ value $<0.0001$ ) shows the fitted model performance was better than the null model.

\section{Results}

\section{Characteristics of respondents}

In this study, the proportion of urban women aged 20-29 years was 1438 (39.9\%) with a mean ( \pm SD) age of 26.4 ( \pm 0.2$)$ years. About $893(24.8 \%), 857$
(23.8 \%), 477 (13.2 \%) and $280(7.8 \%)$ of them were living in Amhara, Oromia, SNNPR, and Tigray regions, respectively. Among participants, 1542 (42.8\%) had only primary level education, and 1602 (44.5\%) married while $798(22.1 \%)$ were in the poorest quintile. Nearly half (47.9\%) had no child (Table 1$)$.

\section{Prevalence of overweight and obesity and its socio-demographic correlates}

The prevalence of overweight and obesity was found to be $435(12.1 \% 95 \%$ CI: 10.1, 14.4) and $99(2.8 \% 95 \%$ CI: 2.1, 3.6), respectively. Thus, about 534 (14.9\%, $95 \%$ CI: $12.4,17.6)$ of urban reproductive age women were overweight and obese (Table 1).

From the multivariable logistic regression analysis; age, region of residence, wealth index, educational status and marital status were significantly associated with being overweight and obese.

The likelihood of being overweight and obese was higher among $20-29$ years (AOR $=2.395 \% \mathrm{CI}$ : 1.4, 3.9), 30-39 years $(\mathrm{AOR}=5.095 \% \mathrm{CI}: 2.9,8.8)$ and $40-49$ years $(\mathrm{AOR}=9.895 \% \mathrm{CI}: 5.1,13.8)$ of age groups compared to the reference age group of 15-19 year olds. With regards to regional distribution, the odds of being overweight and obese was higher among residents of the three Metropolis (AOR $=2.295 \%$ CI: 1.2, 4.2) and among residents of Southern Nations and Nationalities and Peoples Region (SNNPR) (AOR $=2.695 \%$ CI: 1.2, 5.8) compared to urban women in Tigray (Table 2).

The odds of overweight and obesity was 1.8 times (95 \% CI: 1.1, 2.5) higher among those who are in the richest quintile compared to those who are in the poorest quintile. Having a Secondary and above educational level $(\mathrm{AOR}=2.095 \% \mathrm{CI}:(1.3,3.1)$ and being married $(\mathrm{AOR}=2.095 \% \mathrm{CI}:(1.2,3.3)$ were significantly and positively associated with the condition of being overweight and obese (Table 2).

\section{Discussion}

The findings of this study showed that the overall prevalence of overweight and obesity among urban Ethiopian women was $14.9 \%$, which was considerably higher compared to the national average of $5.7 \%$ [26]. However, it is lower than other pocket study conducted in Southwest part of Ethiopia (23.4\%) [18]. Previous studies from the capital, Addis Ababa and among workers of Wonji Shewa sugar factory reported a much higher figure that ranged from 26.7 to $38 \%[15-17,19]$. The availability of more energy dense fast foods and exposure to sedentary life in Addis Ababa and its surroundings (compared to other urban settings in the country) might explain the lower figure for the country as a whole.

This finding is also lower than other studies based on DHS data; from Nigeria (26.7 and 36.4 \%) [14, 27], 
Table 1 Characteristics of non-pregnant reproductive age women in urban Ethiopia, 2011 EDHS, $\left(N^{w}=3602\right)$

\begin{tabular}{|c|c|}
\hline Variables & Frequency (\%) \\
\hline \multicolumn{2}{|l|}{ Age Group ${ }^{\S}$} \\
\hline $15-19$ & $996(27.7)$ \\
\hline $20-29$ & 1438 (39.9) \\
\hline $30-39$ & $783(21.7)$ \\
\hline $40-49$ & $385(10.7)$ \\
\hline \multicolumn{2}{|l|}{ Region of residence } \\
\hline Tigray & $280(7.8)$ \\
\hline Three Metropolis & $886(24.6)$ \\
\hline Amhara & $893(24.8)$ \\
\hline Oromia & $857(23.8)$ \\
\hline SNNPR* & $477(13.2)$ \\
\hline Other Regions & $209(5.8)$ \\
\hline \multicolumn{2}{|l|}{ Wealth quintiles } \\
\hline Poorest & $798(22.1)$ \\
\hline Poorer & $674(18.7)$ \\
\hline Middle & $712(19.8)$ \\
\hline Richer & $709(19.7)$ \\
\hline Richest & 709 (19.7) \\
\hline \multicolumn{2}{|l|}{ Educational status } \\
\hline No formal education & $781(21.7)$ \\
\hline Primary (grade $1-8^{\text {th }}$ ) & $1542(42.8)$ \\
\hline Secondary and above (grade $9^{\text {th }}+$ ) & $1279(35.5)$ \\
\hline \multicolumn{2}{|l|}{ Parity } \\
\hline No child & $1726(47.9)$ \\
\hline 1-4 children & $1485(41.2)$ \\
\hline $5+$ children & $391(10.9)$ \\
\hline \multicolumn{2}{|l|}{ Marital status } \\
\hline Single & $1523(42.3)$ \\
\hline Married & $1602(44.5)$ \\
\hline Divorced/widowed & $477(13.2)$ \\
\hline \multicolumn{2}{|l|}{ Working status } \\
\hline Not working & $1509(41.9)$ \\
\hline White-collar Work & $1450(40.3)$ \\
\hline Manual Work & $619(17.1)$ \\
\hline Others & $24(0.7)$ \\
\hline \multicolumn{2}{|l|}{ Nutritional status } \\
\hline Underweight & $718(19.9)$ \\
\hline Normal & $2350(65.2)$ \\
\hline Overweight & $435(12.1)$ \\
\hline Obesity & $99(2.8)$ \\
\hline
\end{tabular}

*SNNPR $=$ Southern Nations and Nationalities and Peoples Region

$\mathrm{N}^{\mathrm{W}}=$ Total weighted count excluding pregnant women and women with extreme BMI values ( $<12.00 \mathrm{~kg} / \mathrm{m} 2$ and $>50.00 \mathrm{~kg} / \mathrm{m} 2)$

$\S=$ age classification used in EDHS reports (2005 and 2011) under maternal nutritional status section and from seven African countries (average prevalence of $31 \%$ [6]. It is also lower than other pocket studies conducted in Benin (41.3\%), South Africa (56.6 \%), Iran (61.3\%) and India (75.33 \%) [28-31]. This might be due to disparity with the dietary pattern and life style, level of urbanization and economic development of Ethiopia.

In this study, age of women, marital status, wealth status, residence and educational status were found to be significantly associated with overweight and obesity. Consistent with the findings of other studies, the results of this study demonstrated that the prevalence was significantly higher among older women $[16,20,27,32,33]$. The decrease in level of physical activity and a higher intake of energy dense foods as age of women advances could be the possible explanation [34]. Similarly, the condition of being overweight and obese was significantly higher among women in the richest quintile which was consistent with studies from Addis Ababa and Wonji Shewa sugar factory [15, 16, 20] and studies from elsewhere [6, 27, 32, 33, 35]. In developing countries context the wealthier are likely to consume energy dense foods and follow a sedentary life style, hence they are more likely to be overweight and obese.

The prevalence of overweight and obesity was significantly higher among women at high school and above level, which is in line with other similar studies $[6,32,34,35]$. This may be the result of shifts from manual labor to more sedentary occupations and the related decline in physical activity. Like in other studies overweight and obesity was more common among married women [6, 36]. Married are likely to have higher parity which could be linked to adopting more sedentary life style and high energy foods are usually offered for women during postpartum period.

The use of national and sub-nationally representative data and considerations of complex sampling methods are the strengths of this study. The following limitations should be considered while interpreting the results of this study. Firstly, cross-sectional nature of the study does not allow establishing causality of associations. Secondly, important predictors of the outcome variable such as physical activity and total energy intake (nutritional history) are not included owing to use of secondary data. Likewise, there was no data on central obesity since the survey did not collect data on abdominal and waist-to-hip circumference.

\section{Conclusions}

The prevalence of overweight and obesity among urban women in Ethiopia was found to be considerably high compared to the national average. This was particularly more pronounced among older women, those in the richest quintile, with higher education, those living in 
Table 2 Socio-demographic correlates of overweight and obesity among urban reproductive age women in Ethiopia, 2011 EDHS $\left(\mathrm{N}^{\mathrm{W}}=3602\right)$

\begin{tabular}{|c|c|c|c|c|}
\hline \multirow[t]{2}{*}{ Variables } & \multicolumn{2}{|c|}{ Overweight and obesity } & \multirow{2}{*}{$\begin{array}{l}\text { Crude Odds } \\
\text { Ratio }(95 \% \mathrm{Cl})\end{array}$} & \multirow{2}{*}{$\begin{array}{l}\text { Adjusted Odds } \\
\text { Ratio }(95 \% \text { Cl) }\end{array}$} \\
\hline & $\overline{Y e s}(n, \%)$ & No $(n, \%)$ & & \\
\hline \multicolumn{5}{|l|}{ Age Group ${ }^{\S}$} \\
\hline $15-19$ & $44(4.4)$ & $952(95.6)$ & 1 & 1 \\
\hline $20-29$ & $183(12.7)$ & $1255(87.3)$ & $3.2(2.0,5.0)^{*}$ & $2.3(1.4,3.9)^{*}$ \\
\hline $30-39$ & $183(23.4)$ & $600(76.6)$ & $6.7(4.3,10.5)^{*}$ & $5.0(2.9,8.8)^{*}$ \\
\hline $40-49$ & $124(32.2)$ & $261(67.8)$ & $10.3(8.4,16.6)^{*}$ & $9.8(5.1,13.8)^{*}$ \\
\hline \multicolumn{5}{|l|}{ Region of Residence } \\
\hline Tigray & $24(8.6)$ & $256(91.4)$ & 1 & 1 \\
\hline Three Metropolis & $180(20.3)$ & $706(79.7)$ & $2.7(1.4,5.1)^{*}$ & $2.2(1.2,4.2)^{*}$ \\
\hline Amhara & $72(8.1)$ & $821(91.9)$ & $0.9(0.4,2.3)$ & $0.9(0.3,2.4)$ \\
\hline Oromia & $121(14.1)$ & $736(85.9)$ & $1.7(0.8,3.9)$ & $1.5(0.6,3.2)$ \\
\hline SNNPR* & $97(20.3)$ & $380(79.7)$ & $2.7(1.2,6.2)^{*}$ & $2.6(1.2,5.8)^{*}$ \\
\hline Others & $40(19.1)$ & $169(80.9)$ & $2.5(1.2,5.3)^{*}$ & $2.5(1.1,5.4)^{*}$ \\
\hline \multicolumn{5}{|l|}{ Wealth Quintile } \\
\hline Poorest & $84(10.5)$ & $714(89.5)$ & 1 & 1 \\
\hline Poorer & $105(15.6)$ & $569(84.4)$ & $1.6(1.0,2.4)$ & $1.1(0.7,1.8)$ \\
\hline Middle & $140(19.7)$ & $572(80.3)$ & $2.1(1.2,3.8)^{*}$ & $1.6(0.9,2.9)$ \\
\hline Richer & $66(9.3)$ & $643(80.4)$ & $0.9(0,5,1.6)$ & $0.9(0.5,1.6)$ \\
\hline Richest & 139 (19.6) & $570(83.9)$ & $2.1(1.3,3.3)^{*}$ & $1.8(1.1,2.5)^{*}$ \\
\hline \multicolumn{5}{|l|}{ Educational Status } \\
\hline No formal education & $103(13.2)$ & $678(86.8)$ & 1 & 1 \\
\hline Primary $\left(1-8^{\text {th }}\right)$ & $202(13.1)$ & $1340(86.9)$ & $1.0(0.7,1.4)$ & $1.5(1.0,2.3)$ \\
\hline Secondary+ & $229(17.9)$ & $1050(82.1)$ & $1.4(0.9,2.2)$ & $2.0(1.3,3.1)^{*}$ \\
\hline \multicolumn{5}{|l|}{ Parity } \\
\hline No child & $143(8.3)$ & $1583(91.7)$ & 1 & 1 \\
\hline 1-4 children & $312(21.0)$ & $1173(79.0)$ & $3.0(2.1,4.1)^{*}$ & $1.1(0.7,1.7)$ \\
\hline $5+$ children & 79 (20.2) & $312(79.8)$ & $2.8(1.9,4.2)^{*}$ & $0.7(0.4,1.3)$ \\
\hline \multicolumn{5}{|l|}{ Marital Status } \\
\hline Single & $111(7.3)$ & $1412(92.7)$ & 1 & 1 \\
\hline Married & 351 (21.9) & $1251(78.1)$ & $3.6(2.5,5.1)^{*}$ & $2.0(1.2,3.3)^{*}$ \\
\hline Divorced/widowed & $72(15.1)$ & $405(84.9)$ & $2.3(1.5,3.5)^{*}$ & $1.2(0.6,2.3)$ \\
\hline \multicolumn{5}{|l|}{ Occupational status } \\
\hline Not working & $206(13.7)$ & 1303 (86.3) & 1 & 1 \\
\hline White- collar work & $258(17.8)$ & $1192(82.2)$ & $1.4(0.9,1.9)$ & $1.0(0.7,1.4)$ \\
\hline Manual Work & $68(11.0)$ & $551(89.0)$ & $0.8(0.5,1.3)$ & $0.8(0.5,1.2)$ \\
\hline
\end{tabular}

*SNNPR $=$ Southern Nations and Nationalities and Peoples Region

$\mathrm{N}^{\mathrm{W}}=$ Total weighted count excluding pregnant women and women with extreme BMI values $\left(<12.00 \mathrm{~kg} / \mathrm{m}^{2}\right.$ and $\left.>50.00 \mathrm{~kg} / \mathrm{m}^{2}\right)$

$\S=$ age classification used in EDHS reports (2005 and 2011) under maternal nutritional status section

the three metropolises (Addis Ababa, Dire Dawa and Harari) and married women. Based on the findings of this and other studies, it is imperative to design targeted overweight reduction programs with special emphasis on older, educated and well to do women, and those living in the big cities. There is also a need for more indepth studies that account for important predictors including level of physical activity, nutritional history, and indicators of central obesity such as waist and abdominal circumference. 


\section{Abbreviations}

BMI, body mass index; Cl, confidence interval; CSA, Central Statistical Agency; DALYs, global disability adjusted life years; DHS, Demographic Health Survey; EDHS, Ethiopia Demographic Health Survey; $\mathrm{Kg} / \mathrm{m}^{2}$, kilogram per meter square; SNNPR, Southern Nations Nationalities and Peoples Region; USAID, United States Agency for International Development

\section{Acknowledgement}

We would like to thank MEASURE DHS staff and discussion forum participants for their timely reply to our questions. We would like to thank Addis Ababa University, for providing funding support to conduct this work. Finally, we extend our acknowledgement to Central Statistical Agency (CSA) and MEASURE DHS project for providing free access to the data. We would also thank Alemayehu Work and Yared mekonnen for their support during the analysis process. Finally, our gratitude also goes to Tariku Dejene, Eyob Ambaw and Mereon Genene for their English language and grammar corrections.

\section{Funding}

The funding for this study was granted by Addis Ababa University. The funding body had no influence on study design, data collection, analysis and interpretation of data, writing of the manuscript and in the decision to submit the manuscript for publication.

\section{Availability of data and materials}

"The data that support the findings of this study are available from MEASURE DHS project but restrictions apply to the availability of these data, which were used under license for the current study, and so are not publicly available. Data are however available from the MEASURE DHS project upon reasonable online request after submission of concept paper".

\section{Authors' contributions}

SA participated in proposal development, conducting the analysis, writing the manuscript. He SS conceived the idea, and was involved in proposal writing, analysis and manuscript write up. KY reviewed the manuscript and provided useful comments during the analysis and Manuscript write-up. All authors read and approved the manuscript.

\section{Competing interests}

The authors declare that they have no competing interests.

\section{Consent for publication}

"Not applicable."

\section{Ethics approval and consent to participate}

The study proposal got ethical approval from Addis Ababa University, School of Public Health and formal letter of permission was obtained from measure DHS project website to access the dataset.

\section{Author details}

${ }^{1}$ Department of Epidemiology and Biostatistics, School of Public Health, College of Medicine and Health Science, Wolayta Sodo University, PO Box: 138, Wolayta Sodo, Ethiopia. ${ }^{2}$ School of Public Health, College of Health Sciences, Addis Ababa University, PO Box: 9086, Addis Ababa, Ethiopia. ${ }^{3}$ Department of Public Health, College of Medicine and Health Science, Debre Markos University, PO Box: 269, Debre Markos, Ethiopia.

Received: 8 October 2015 Accepted: 15 July 2016

Published online: 26 July 2016

\section{References}

1. Ng M, Fleming T, Thomson B, et al. Global, regional and national prevalence of overweight and obesity in children and adults 1980-2013: A systematic analysis. Lancet. 2014;384(9945):766-81.

2. World Health Organization: Global health risks: mortality and burden of disease attributable to selected major risks. Geneva: World Health Organization; 2009.

3. World Health Organization: Global status report on non-communicable diseases. Geneva: World Health Organization; 2011.

4. Stevens GA, et al. National, regional, and global trends in adult overweight and obesity prevalence. Popul Health Metrics. 2012;10:22.
5. Lim SS, Vos T, Flaxman AD, et al. A comparative risk assessment of burden of disease and injury attributable to 67 risk factors and risk factor clusters in 21 regions, 1990-2010: a systematic analysis for the Global Burden of Disease Study 2010. Lancet. 2012;380:2224-60.

6. Abdhalah KZ, Jean CF, Rhoune O. Overweight and obesity in urban Africa: A problem of the rich or the poor? BMC Public Health. 2009;9:465.

7. Sodjinou R, Agueh V, Fayomi B. Obesity and cardio-metabolic risk factors in urban adults of Benin: relationship with socio-economic status, urbanization, and lifestyle patterns. BMC Public Health. 2008;8:84.

8. Campbell T. Emerging disease burdens and the poor in cities of the developing world. J Urban Health. 2007;84(3):54-64.

9. Kamadjeu RM, Edwards R, Atanga JS, et al. Anthropometry measures and prevalence of obesity in the urban adult population of Cameroon: an update from the Cameroon Burden of Diabetes Baseline Survey. BMC Public Health. 2006;6:228.

10. Omran AR. The epidemiologic transition theory: a preliminary update. J Trop Pediatr. 1983;29:305-16.

11. Popkin BM, Doak CM. The obesity epidemic is a worldwide phenomenon. Nutr Rev. 1998;56:106-14.

12. World Health Organization: Non-communicable disease country profile. Geneva: World Health Organization; 2011.

13. Abubakari AR, Lauder W, Agyemang C, et al. Prevalence and time trends in obesity among adult West African populations: a meta-analysis. Obes Rev. 2008;9(4):297-311.

14. Kandala NB, Stranges S. Geographic variation of overweight and obesity among women in Nigeria: a case for nutritional transition in Sub-Saharan Africa. PLoS One. 2014;9(6):e101103.

15. Birhane T, et al. Urban food insecurity in the context of high food prices: a community based cross sectional study in Addis Ababa, Ethiopia. BMC Public Health. 2014;14:680.

16. Henok A, et al. Effect of shit-work on Hypertension among Factory Workers in Ethiopia. Am J Clin Exp Med. 2015;3(4):142-8.

17. Wai WS, Birhane Y, Dhami RS, et al. Comparison of measures of adiposity in identifying cardiovascular disease risk among Ethiopian adults. Obesity. 2012;20(9):1887-95.

18. Solomon T, et al. Risk Factors for Cardiovascular Diseases. Ethiop J Health Sci. 2010;20(2):123-26.

19. Addis Continental Institute of Public Health (ACIPH), University of Washington. Survey of Non Communicable Diseases among Bank Employees and Teachers in Addis Ababa, Ethiopia. Preliminary result. 2010.

20. Tebekaw Y, Teller C, Ramos K. The burden of underweight and overweight among women in Addis Ababa, Ethiopia. BMC Public Health. 2014;14:1126.

21. Federal Democratic Republic of Ethiopia, Ministry of Health: Health Sector Transformation Plan (HSTP), 2015/16 - 2019/20. Addis Ababa, Ethiopia: Federal Ministry of Health; 2015.

22. Neupane S, Prakash KC, Teye-Doku D. Overweight and obesity among women: analysis of demographic and health survey data from 32 Sub-Saharan African Countries. BMC Public Health. 2016;16:30.

23. Popkin BM, Gordon-Larsen P. The nutrition transition: worldwide obesity dynamics and their determinants. Int J Obes Relat Metab Disord. 2004;28(3):S2-9.

24. Keding GB, Msuya JM, Maass BL, Krawinkel MB. Obesity as a public health problem among adult women in rural Tanzania. Glob Health Sci Pract. 2013;1(3):359-71.

25. Central Statistical Agency: Summary and Statistical Report of the 2007 Population and Housing Census of Ethiopia. Addis Ababa, Ethiopia: Central Statistical Agency; 2008.

26. Central Statistical Agency and ICF Macro. Ethiopian demographic and health survey. Final report. Calverton: ICF Macro; 2011.

27. Uthman OA. Patterns, distribution, and determinants of under- and over nutrition among women in Nigeria: a population-based analysis. J Public Health. 2009;17(5):289-99.

28. Gbary AR, Kpozehouen A, Houehanou YC, et al. Prevalence and risk factors of overweight and obesity: findings from a cross-sectional communitybased survey in Benin. Glob Epidemi Obes. 2014;2:3.

29. Puoane T, Steyn K, Bradshaw D, et al. Obesity in South Africa: the south african demographic and health survey. Obes Res. 2002;10(10):1038-48.

30. Mohsen J, Masoud A, Willett WC, et al. First nationwide survey of prevalence of overweight, underweight, and abdominal obesity in Iranian adults. Obesity. 2007;15(11):2797-808. 
31. Kaur G, Singh SP, Singh AP. Prevalence of overweight and obesity in Urban and Rural women of Punjab. Hum Bio Rev. 2013;2(4):06-313.

32. Yarlini B, Eduardo V. Nationally representative surveys show recent increases in the prevalence of overweight and obesity among women of reproductive age in Bangladesh, Nepal, and India. J Nutr. 2009; 139(11):2139-44.

33. Neuman M, Finlay JE, Davey Smith G, Subramanian SV. The poor stay thinner: stable socioeconomic gradients in BMl among women in lower- and middleincome countries. Am J Clin Nutr. 2011;94(5):1348-57.

34. Alemu E, Atnafu A, Yitayal M, Yimam K. Prevalence of Overweight and/or Obesity and Associated Factors among High School Adolescents in Arada Sub city, Addis Ababa, Ethiopia. J Nutr Food Sci. 2014;4:261.

35. Subramanian SV, Perkins JM, O"zaltin E, Davey Smith G. Weight of nations: a socioeconomic analysis of women in low- to middle-income countries. Am J Clin Nutr. 2011:93(2):413-21.

36. World Health Organization. Preventing and managing the Global Obesity Epidemic. Geneva: Report of WHO Consultation on Obesity; 1998.

\section{Submit your next manuscript to BioMed Central} and we will help you at every step:

- We accept pre-submission inquiries

- Our selector tool helps you to find the most relevant journal

- We provide round the clock customer support

- Convenient online submission

- Thorough peer review

- Inclusion in PubMed and all major indexing services

- Maximum visibility for your research

Submit your manuscript at www.biomedcentral.com/submit 